\title{
Expression of multidrug resistance-associated protein 2 is involved in chemotherapy resistance in human pancreatic cancer
}

\author{
BUNJIRO NOMA, TAMITO SASAKI, YOSHIFUMI FUJIMOTO, \\ MASAHIRO SERIKAWA, KENSO KOBAYASHI, MOTOKI INOUE, HIROSHI ITSUKI, \\ MICHIHIRO KAMIGAKI, TOMOYUKI MINAMI and KAZUAKI CHAYAMA \\ Department of Medicine and Molecular Science, Hiroshima University Graduate \\ School of Biomedical Sciences, 1-2-3 Kasumi, Minami-ku, Hiroshima 734-8551, Japan
}

Received July 29, 2008; Accepted October 2, 2008

DOI: 10.3892/ijo_00000108

\begin{abstract}
Despite the recent introduction of the new anticancer agents gemcitabine (GEM) and TS-1, as well as combination regimens such as GEM plus cisplatin (CDDP), pancreatic cancer treatment remains relatively ineffective. Both intrinsic and acquired resistance to chemotherapy are major roadblocks to the successful treatment of pancreatic cancer patients. The aims of this study were to examine the expression of multidrug resistance-associated proteins (MRPs) MRP1, MRP2 and MRP3 and to evaluate the correlation between MRP2 expression and CDDP resistance in human pancreatic cancer. Five human pancreatic cancer cell lines and several surgically resected pancreatic cancer tissues were subjected to reversetranscriptase (RT)-PCR, real-time PCR and immunohistochemical analysis. While MRP1 and MRP2 mRNA was expressed in all cell lines, MRP3 mRNA was only detected in two cell lines. In resected pancreatic cancer tissues, only MRP2 mRNA was expressed and it was overexpressed compared with normal pancreatic tissues. MRP2 protein expression was observed in $77.5 \%$ (31/40) of cancer tissues, primarily in the cytoplasm of cancer cells, but was not observed in normal pancreatic tissue. Two CDDP-resistant pancreatic cancer cell line SUIT-2 variants, SUIT-2-CD3 and SUIT-2-CD4, were established by continuously administering $10 \mathrm{nM}$ CDDP to SUIT-2 cell lines for 3 and 4 months, respectively. Incubation of these cells with CDDP in the presence of anti-MRP2 antibody or the MRP2 inhibitor MK-571 in a growth inhibition assay demonstrated that the CDDP-resistant variants were more resistant to CDDP than the parent cell line and this resistance was diminished by either anti-MRP2 antibody or
\end{abstract}

Correspondence to: Dr Bunjiro Noma, Department of Medicine and Molecular Science, Hiroshima University Graduate School of Biomedical Sciences, 1-2-3 Kasumi, Minami-ku, Hiroshima 734-8551, Japan

E-mail: bunjiro@hiroshima-u.ac.jp

Key words: multidrug resistance-associated protein 2, pancreatic cancer, cis-diamminedichloroplatinum, real-time PCR, drug resistance
MK-571. Moreover, RT-PCR and real-time PCR revealed that while induction of MRP2 mRNA expression was increased in CDDP-resistant compared with parent cells, MRP1 and MRP3 expression remained unchanged. These observations suggest that MRP2 may correlate to intrinsic and acquired resistance for CDDP in human pancreatic cancer.

\section{Introduction}

Pancreatic cancer is currently the fifth leading cause of cancer death in Japan (1) and the incidence of pancreatic cancerrelated death is steadily increasing. At the time of diagnosis, many patients have locally advanced or metastatic disease. Consequently, chemotherapy remains the only treatment strategy for patients with non-resectable disease $(2,3)$. In recent years, gemcitabine (GEM) and TS-1 (tegafur, gimestat and otastast potassium) have become standard therapies for patients with advanced pancreatic cancer; however, these new treatments have not led to improved prognoses. The efficacy of combination chemotherapy, such as GEM plus cisplatin [cis-diamminedichloroplatinum (CDDP)], has also been disappointing (4-6). Overall, the response of pancreatic cancer to chemotherapy is generally quite limited, due in part to resistance to chemotherapeutic agents $(2,7)$.

Acquired drug resistance in cancer cells is a major roadblock to effective chemotherapy. In general, multidrug resistance is caused by $\mathrm{P}$-glycoprotein and multidrug resistance proteins (MRPs), which belong to the ATP-binding cassette transporter family (8-11). The human MRP family currently has nine members, of which at least three (MRP1, MRP2 and MRP3) are known to be correlated with chemoresistance (9,12-14). The best characterized are MRP1 and MRP2. MRP1 is a $190-\mathrm{kDa}$ glycoprotein that mediates the extra- and intracellular transport of many glutathione S-conjugates $(8,15-17)$. Its preferred substrates are organic anions, e.g., drugs conjugated to glutathione, sulphate, or glucuronate (9). MRP2, or human canalicular multispecific organic anion transporter (cMOAT), was first identified from the canalicular membrane of hepatocytes and is also involved in the transport of organic anions across the plasma membrane. In addition, MRP2 has been found to be overexpressed in a number of CDDP-resistant human cancer cell lines, including hepato- 
cellular carcinoma, hepatoblastoma, bladder cancer, prostate cancer, colon cancer, ovarian cancer, adrenocortical cancer, and melanoma cells (18-21). In vitro data have also suggested that MRP2 may play an important role in multidrug resistance during chemotherapy (19-24). Finally, MRP3 has been shown to transport methotrexate (MTX) and etoposide, but not glutathione (25).

Liu et al have reported that docetaxel-related drug resistance in pancreatic cancer cell lines is primarily mediated by P-glycoprotein and has no relationship to MRPs or lung resistance protein $(26,27)$. In contrast, Miller et al reported that intrinsic drug resistance in pancreatic duct cancer may be due in part to the presence of MRPs (28). Overall, few studies have investigated the expression of MRPs in pancreatic cancer and there have been no studies about MRP2 expression and CDDP resistance in this disease. The aims of the present study were to examine the expression profile of MRPs and to evaluate the correlation between MRP2 expression and CDDP resistance in human pancreatic cancer.

\section{Materials and methods}

Cell culture and tumor tissues. Four human pancreatic cancer cell lines, PANC-1, MIAPaCa-2, Capan-2 and BxPC3, were purchased from the American Type Culture Collection (Rockville, MD). The pancreatic cancer cell line SUIT-2 was purchased from the Health Science Research Resources Bank (Osaka, Japan). Cells were maintained in Dulbecco's modified Eagle's medium (DMEM; Gibco-BRL, Grand Island, NY), pH 7.4, containing $100 \mathrm{U} / \mathrm{ml}$ penicillin-streptomycin (Sigma Chemical Co., St. Louis, MO) and $10 \%$ fetal bovine serum (FBS; Iwaki, Tokyo, Japan) and were grown in $25-\mathrm{cm}^{2}$ plastic flasks (Becton-Dickinson, Franklin Lakes, NJ) in 5\% $\mathrm{CO}_{2}$ at $37^{\circ} \mathrm{C}$. We examined 40 pancreatic cancer tissue specimens that were surgically resected between 1995 and 2006 at the Hiroshima University Hospital. Five specimens were used for reverse transcriptase (RT)-PCR and six were used for real-time PCR, after informed consent was obtained from patients.

$R T-P C R$. RT-PCR analysis was performed, as described previously (29). Briefly, total RNA was extracted from five human pancreatic cancer cell lines and five surgically resected pancreatic cancer tissues using a FastRNA ${ }^{\circledR}$ kit, Green (Bio 101, Inc., Vista, CA), according to the manufacturer's instructions. A sample containing $200 \mathrm{ng}$ total RNA in a $20-\mu \mathrm{l}$ mixture was reverse-transcribed with Moloney murine leukemia virus reverse transcriptase (Toyobo Co., Ltd., Osaka, Japan) at $42^{\circ} \mathrm{C}$ for $30 \mathrm{~min}$ in the presence of $25 \mathrm{pmol}$ oligo (dT) 20 primer. Subsequently, $20 \mu 1$ reverse-transcribed mixture was subjected to PCR in a $100-\mu 1$ reaction mixture in the presence of $1 \mathrm{U}$ Kod Plus ${ }^{\mathrm{TM}}$ (Toyobo) and $20 \mathrm{pmol}$ of each primer. The following cycling conditions were used: 40 cycles consisting of denaturation at $94^{\circ} \mathrm{C}$ for $30 \mathrm{sec}$, annealing at $56^{\circ} \mathrm{C}(\mathrm{MRP} 1), 50^{\circ} \mathrm{C}$ (MRP2), $54^{\circ} \mathrm{C}$ (MRP3), or $60^{\circ} \mathrm{C}$ [glyceraldhyde-3-phosphate dehydrogenase $(\mathrm{G} 3 \mathrm{PDH}$; control)] for $30 \mathrm{sec}$ and extension at $72^{\circ} \mathrm{C}$ for $60 \mathrm{sec}$. A 10- $\mu 1$ sample of each PCR product was separated in a $1.5 \%$ agarose gel, stained with SYBR-Green (Molecular Probes, Eugene, OR) and visualized using ultraviolet light. The following primer sequences were used: MRP1, sense 5'-AGT GAC CTC TGG TCC TTA AAC AAG G-3' and antisense 5'-GAG GTA GAG AGC AAG GAT GAC TTG C-3'; MRP2, sense 5'-AGG ATG ACA TCA GAA ATA GAG ACC-3' and antisense 5'-CTA CTC CAT CAA TGA TAA TCT GAC C-3'; MRP3, sense 5'-GAT ACG CTC GCC ACA GTC C-3' and antisense 5'-CAG TTG GCC GTG ATG TGG CTG-3'; and G3PDH, sense 5'-TCC ACC ACC CTG TTG CTG TA-3' and antisense 5'-ACC ACA GTC CAT GCC ATC AC-3'.

Immunohistochemical staining. Consecutive 4- $\mu \mathrm{m}$ sections were cut from each specimen block. Immunohistochemical staining was performed using a Vectastain ${ }^{\circledR}$ Elite ABC kit (Vector Laboratories, Inc., Burlingame, CA). Sections were subjected to immunohistochemical analysis of MRP2 expression using a mouse monoclonal antibody (M2III-6; Sanbio b.v., Uben, The Netherlands) at a 1:50 dilution. Tissues in which $>10 \%$ of cells were stained were considered to be positive.

Establishment of CDDP-resistant SUIT-2 variants. Two CDDP-resistant variants of the SUIT-2 pancreatic cancer cell line, SUIT-2-CD3 and SUIT-2-CD4, were cultivated by continuous exposure to $10 \mathrm{nM}$ CDDP for 3 and 4 months, respectively. Briefly, SUIT-2 cells were grown as monolayers in culture medium at $37^{\circ} \mathrm{C}$ in a $5 \% \mathrm{CO}_{2}$ humidified atmosphere and exposed to $10 \mathrm{nM}$ CDDP for 3 or 4 months, with fresh culture medium and drug added every 3 days. Cells were then maintained in a CDDP-free culture medium for at least 3 weeks before analysis.

Growth inhibition assay. We used a cell proliferation ELISA system $^{\mathrm{TM}}$ (Amersham Pharmacia Biotech, Piscataway, NJ) (30) to measure cell growth inhibition, according to the manufacturer's instructions. Briefly, SUIT-2, SUIT-2-CD3, and SUIT-2-CD4 cells $\left(5 \times 10^{3}\right)$ were plated in 96-well plates and treated with various concentrations of CDDP $(0-16 \mu \mathrm{M})$ and anti-MRP2 antibody (0-25 ng/ml) or MK-571 $(0-20 \mu \mathrm{M})$ (Biomol International, LP, USA), which is reported to be an MRP2 inhibitor $(31,32)$, in DMEM supplemented with $0.1 \%$ FBS. After 72 h, 5-bromo-2'-deoxyuridine (BrdU) was added to a final concentration of $10 \mu \mathrm{M}$ and the reaction mixture was incubated for $2 \mathrm{~h}$ at $37^{\circ} \mathrm{C}$. Sequentially, cells were fixed with ethanol, blocked with blocking solution and incubated with anti-BrdU for $90 \mathrm{~min}$. Finally, cells were reacted with 3,3',5,5'-tetramethylbenzidine (TMB) substrate and the absorbance at $450 \mathrm{~nm}$ of supernatant aliquots from each well was measured using an automatic plate analyzer (ETY-3A; Toyo Sokki, Tokyo, Japan). Each experiment was performed two times in triplicate.

Preparation of MRP2 and G3PDH cDNA for standard curves. Select MRP2 and G3PDH PCR products were gel-purified, cloned by ligation into the pGEM $^{\circledR}-\mathrm{T}$ easy vector (Promega, Madison, WI) and transformed into JM 109 competent bacteria (Toyobo). Plasmid DNA was extracted by the Automatic DNA Isolation System ${ }^{\mathrm{TM}}$ (Kurabo, Osaka, Japan). Sequencing reactions were analyzed in an automatic sequencing system (ABI 310; Applied Biosystems, Foster City, CA) using the BigDye terminator cycle sequencing reaction kit (Applied 
A

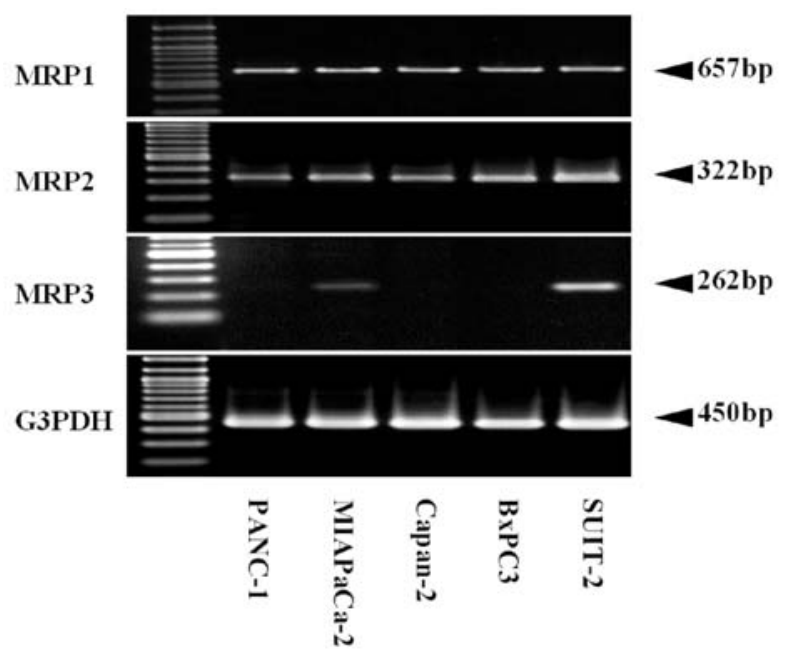

B

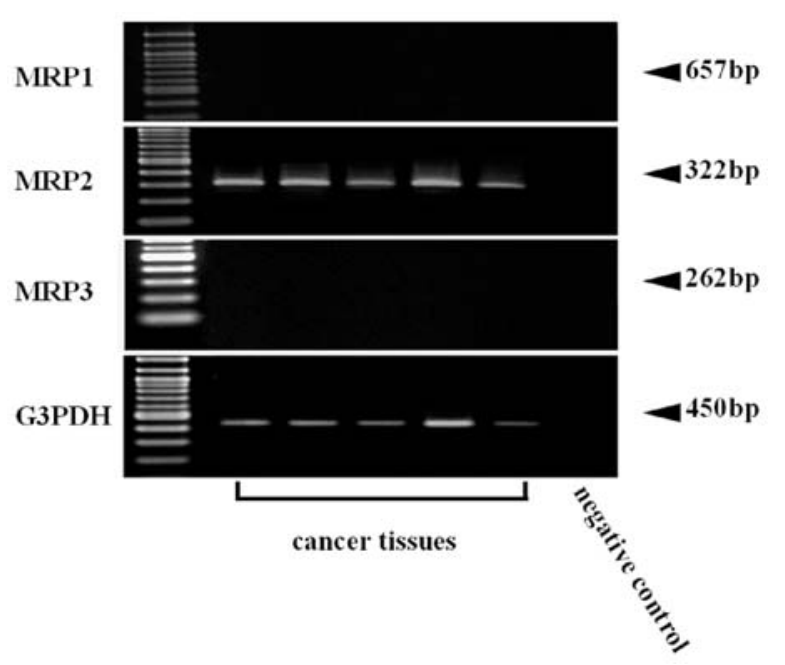

Figure 1. Expression of MRP mRNA in human pancreatic cancer cells and resected pancreatic cancer tissues (RT-PCR). Total RNA from pancreatic cancer cells was extracted and amplified by RT-PCR using specific primer sets. (A) The expected MRP1 and MRP2 mRNA bands were detected in all pancreatic cancer cell lines. MRP3 mRNA was only expressed in MIAPaCa-2 and SUIT-2 cells. (B) MRP2 mRNA, but not MRP1 or MRP2 mRNA, was expressed in resected pancreatic cancer tissues.

Biosystems). The derived MRP2 and G3PDH gene sequences were confirmed by comparison with corresponding germline genes using Genbank (EMBL). Isolated cDNA fragments were used as templates for external standards for use in real-time PCR.

Real-time PCR. Total RNA was extracted and reversetranscribed as described above. PCR reactions were monitored in real-time with the LightCycler ${ }^{\circledR}$ system (Roche Molecular Systems, Inc., Pleasanton, CA) and LightCycler FastStart DNA Master SYBR-Green I kit (Roche Diagnostics, Meylan, France), which binds preferentially to double-stranded DNA. The 20- $\mu 1$ reaction mixtures contained LightCycler FastStart DNA Master SYBR-Green I, $3 \mathrm{mM} \mathrm{MgCl}_{2}$, primers (each at $0.5 \mu \mathrm{M})$ and $2 \mu 1$ template. The amplification program with MRP2 and G3PDH primers included an initial denaturation step at $95^{\circ} \mathrm{C}$ for $10 \mathrm{~min}$ and 40 cycles of denaturation at $95^{\circ} \mathrm{C}$ for $15 \mathrm{sec}$, annealing at $50^{\circ} \mathrm{C}(\mathrm{MRP} 2)$ or $60^{\circ} \mathrm{C}(\mathrm{G} 3 \mathrm{PDH})$ for $5 \mathrm{sec}$ and extension at $72^{\circ} \mathrm{C}$ for $10 \mathrm{sec}$. The temperature transition rate was $20 \% \mathrm{sec}$. After amplification, a melting curve was acquired by heating the product at $20^{\circ} \mathrm{C} / \mathrm{sec}$ to $95^{\circ} \mathrm{C}$, cooling it at $20^{\circ} \mathrm{C} / \mathrm{sec}$ to $65^{\circ} \mathrm{C}$, maintaining it at $65^{\circ} \mathrm{C}$ for $15 \mathrm{sec}$ and then slowly heating at $0.1^{\circ} \mathrm{C} / \mathrm{sec}$ to $95^{\circ} \mathrm{C}$. With this technique, reactions are characterized using the time during cycling when amplification of the PCR products is first detected, rather than the amount of PCR product accumulated after a fixed number of cycles. The higher the starting quantity of the template, the earlier a significant increase in fluorescence is observed. The threshold cycle is defined as the fractional cycle number at which fluorescence passes a fixed threshold above baseline. For each sample, the amounts of the MRP2 and G3PDH mRNA were determined from a standard curve. Quantities of MRP2 and G3PDH mRNA were determined by comparison to a DNA external standard. Product specificity was determined by melting curve analysis, as described in the LightCycler handbook and by visualization of PCR products on agarose gels and direct DNA sequencing. Results are expressed as ratios of MRP2 mRNA to G3PDH mRNA.

Statistical analysis. Statistical analysis was performed using Scheffé's F test. Results are presented as the average \pm SD of triplicate samples from at least two independent experiments. A probability level of $\mathrm{p}<0.05$ was considered statistically significant.

\section{Results}

MRP1, MRP2 and MRP3 mRNA expression in pancreatic cancer cell lines and resected pancreatic cancer tissue (RT$P C R)$. First, MRP1, MRP2 and MRP3 mRNA expression in pancreatic cancer cell lines and surgical tissues was examined by RT-PCR analysis. As shown in Fig. 1A, MRP1 and MRP2 mRNA was detected in all pancreatic cancer cell lines. In contrast, MRP3 mRNA was only detected in MIAPaCa-2 and SUIT-2 cells. MRP2 mRNA was detected in all five resected pancreatic cancer tissue specimens examined; however, neither MRP1 nor MRP3 mRNA was detected in these specimens (Fig. 1B).

Semiquantitative analysis of MRP2 $m R N A$ expression in resected pancreatic cancer tissue (real-time PCR). Since MRP2 mRNA was detected in all cancer cell lines and resected cancer tissues, we next performed semiquantitative analysis of MRP2 mRNA expression using cancerous and normal pancreatic tissues. Initially, to determine whether the LightCycler assay system was reliable for semiquantification of MRP2 mRNA, serial concentrations of the derived MRP2 gene were amplified and fluorescence intensities were measured. MRP2 was linearly amplified by the LightCycler, depending on the template concentration. The run profile and standard curve of MRP2 are shown in Fig. 2A and B. Subsequently, we performed real-time PCR on six pancreatic 
A

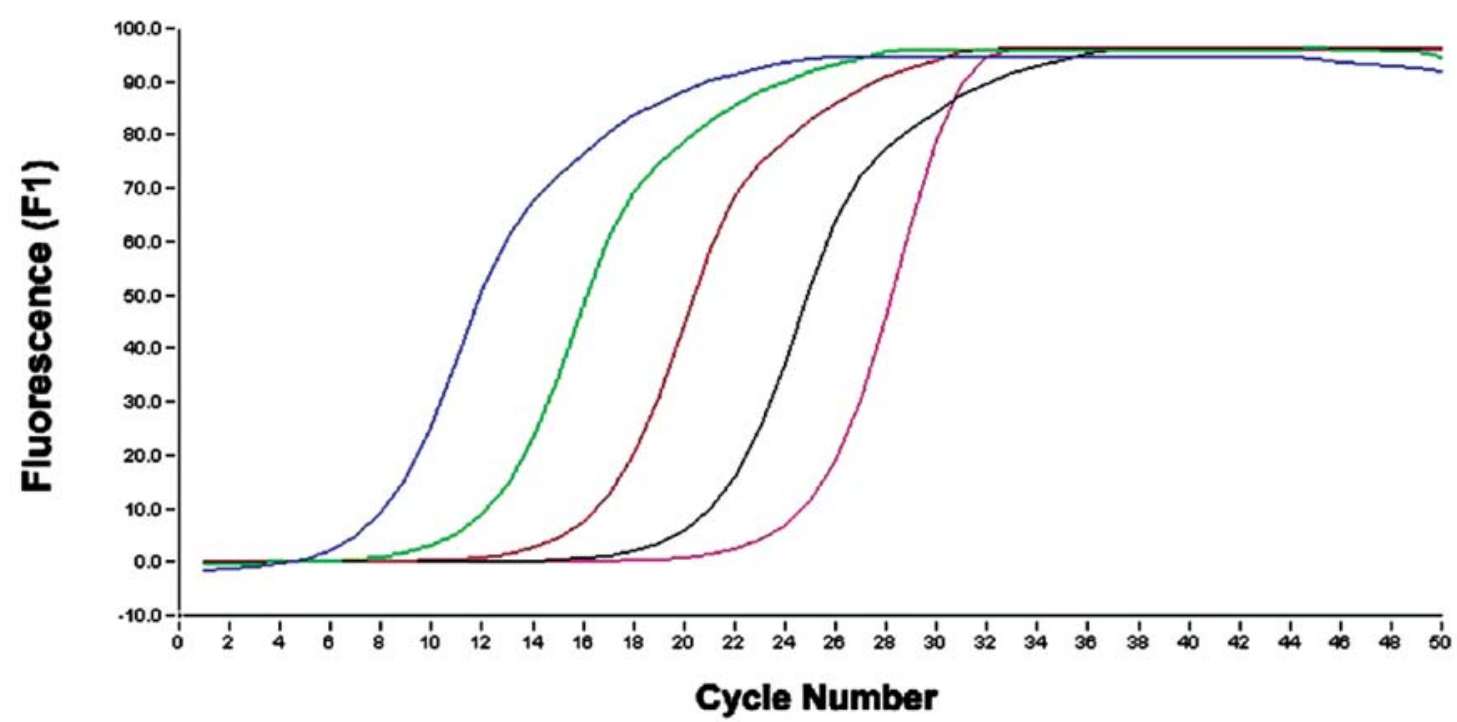

B

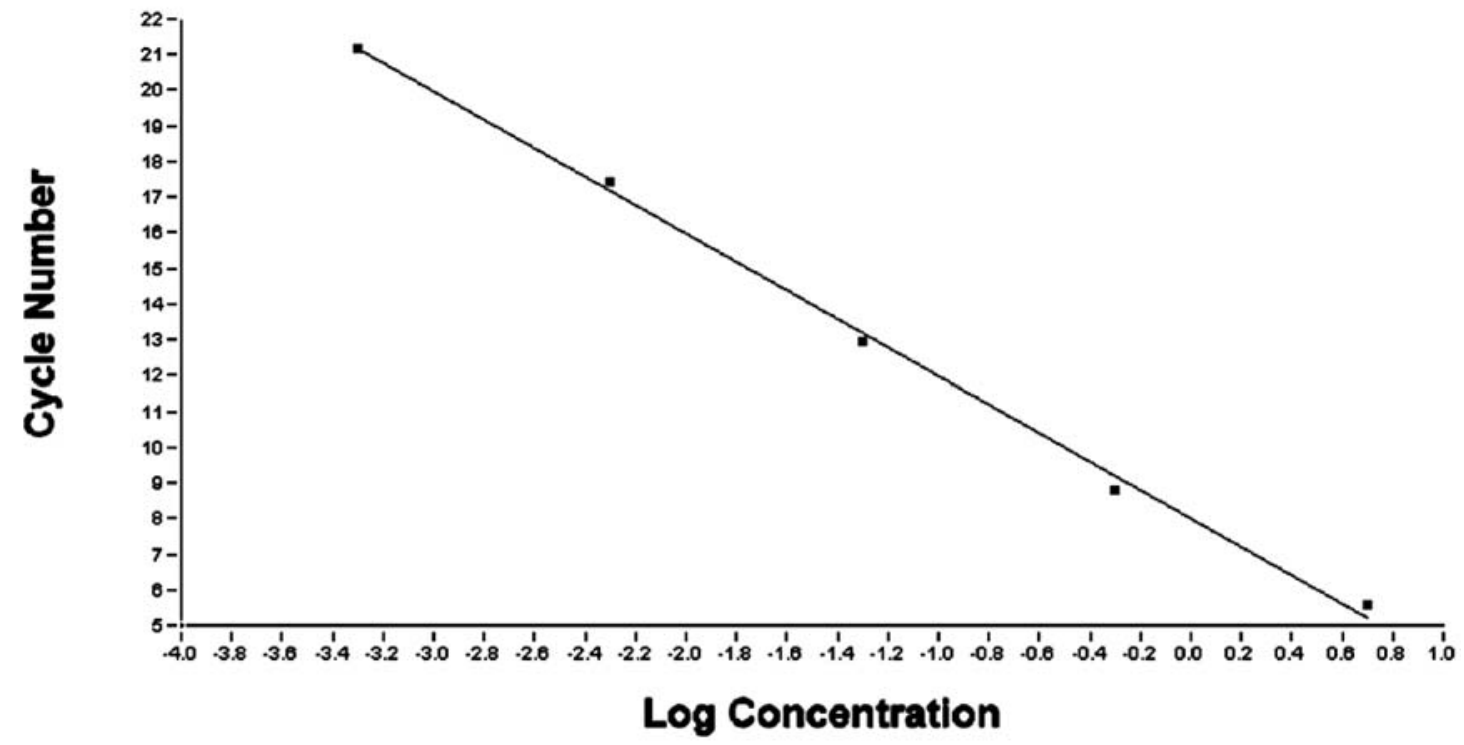

C

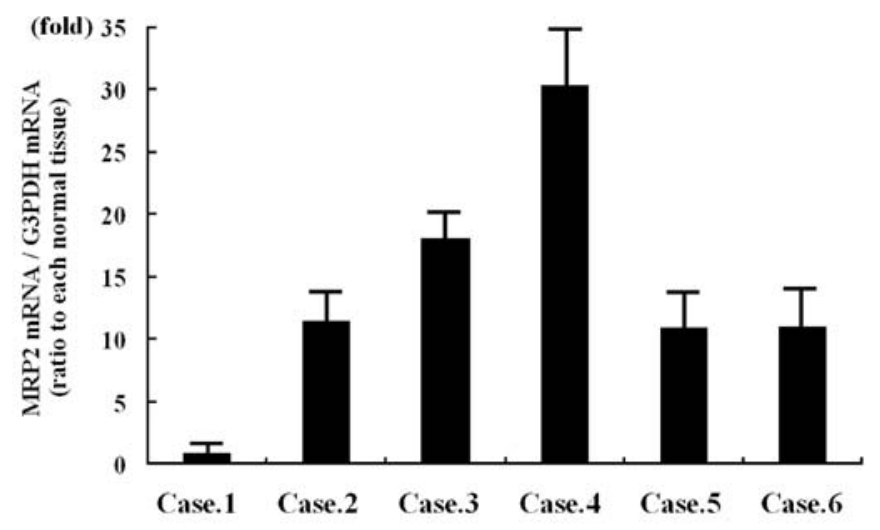

cancer tissues and matched normal pancreatic tissue. We found that MRP2 mRNA expression was 1.2- to 30-fold higher in cancer lesions than in matched normal pancreatic tissue (Fig. 2C).
Figure 2. Semiquantitative analysis of MRP2 mRNA expression. Using the LightCycler system, serial concentrations of derived DNA fragments of MRP2 $\left(5 \times 10^{-1}-5 \times 10^{3} \mathrm{ng} / \mathrm{ml}\right)$ were amplified and the fluorescence intensities were measured, as described in Materials and methods. (A) Run profile of fluorescence vs. PCR cycle (MRP2 external standard). (B) Standard curve for MRP2 mRNA. MRP2 fragments were linearly amplified by the LightCycler depending on the template concentration. (C) Total RNA from pancreatic cancer tissues and normal pancreas was extracted and reverse-transcribed. MRP2 mRNA was overexpressed in human pancreatic cancer tissues compared to matched normal pancreas.

Expression of MRP2 protein in resected pancreatic cancer tissue (immunohistochemistry). We used immunohistochemistry to evaluate MRP2 protein expression in 40 pancreatic cancer tissues obtained by surgical resection. Immunohistochemical staining revealed that MRP2 protein was expressed in 31 out of 40 specimens $(77.5 \%)$, with immunoreactive signals observed primarily in the cytoplasm of cancer cells, as well as in the cell membrane (Fig. 3). In contrast, no evidence of MRP2 protein was observed in surrounding normal pancreatic tissues, including pancreatic 


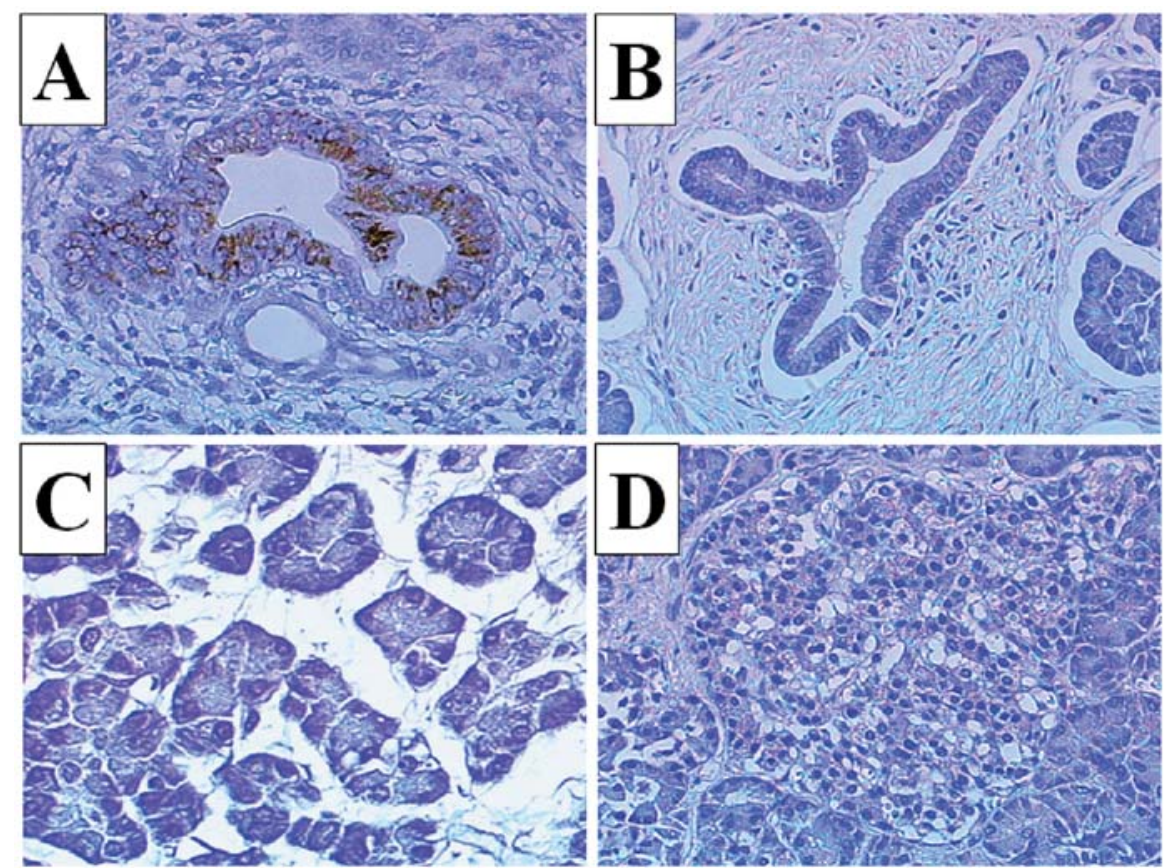

Figure 3. Immunohistochemical analysis of MRP2 protein expression in pancreatic cancer tissue. MRP2 protein was detected in the membrane and cytoplasm of tumor cells in resected pancreatic cancer tissue. In contrast, MRP expression was not observed in surrounding normal pancreatic tissues. (A) Pancreatic cancer; (B) normal pancreatic duct; (C) normal acini and (D) normal islet of Langerhans. Magnification, x200.

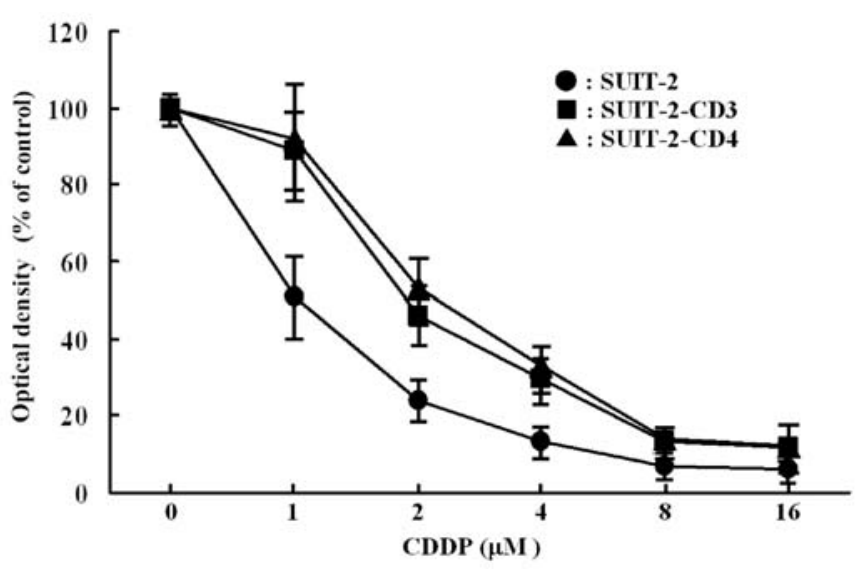

Figure 4. Establishment of CDDP-resistant SUIT-2 cells. CDDP-resistant SUIT-2 cells were cultivated in the presence of CDDP and acquired resistance to CDDP was evaluated using a cell proliferation ELISA system. A representative percent ratio was obtained by comparing treated cells with non-treated cells. Both SUIT-2-CD3 and SUIT-2-CD4 cells were more resistant to CDDP than was the parent cell line.

ducts, acini and islets of Langerhans. These results demonstrate that MRP2 protein is highly and preferentially expressed in pancreatic cancer lesions.

Growth inhibition assay. We next used a cell proliferation ELISA system to determine whether SUIT-2-CD3 and SUIT2-CD4 cells are resistant to CDDP. Treatment of SUIT-2 cells with $1 \mu \mathrm{M}$ CDDP induced a cell growth inhibition rate of $50 \%$ (Fig. 4). However, the cell growth inhibition rates in SUIT-2CD3 and SUIT-2-CD4 cells were reduced to 10 and $8 \%$, respectively, following CDDP treatment. The 50\% inhibitory concentrations of CDDP against SUIT-2, SUIT-2-CD3 and SUIT-2-CD4 cells were $1.2,1.9$ and $2.0 \mu \mathrm{M}$, respectively. These results indicate that continuous administration of CDDP to SUIT-2 cells over 3-4 months results in CDDP resistance.

Induction of MRP2 mRNA expression by CDDP. We studied whether CDDP resistance in pancreatic cancer cells involves changes in MRP2 expression. RT-PCR analysis demonstrated that MRP2, but not MRP1 or MRP3, is overexpressed in CDDP-resistant SUIT-2 cells (Fig. 5). A semiquantitative analysis using the LightCycler system was then used to confirm that induction of MRP2 mRNA expression is significantly increased by 1.5 - and 2.5 -fold in SUIT-2-CD3 and SUIT-2-CD4 cells, respectively, compared to parent SUIT-2 cells (Fig. 6).

Reduction of resistance to CDDP. SUIT-2 and SUIT-2-CD3 cells were treated with various concentrations of CDDP, as well as anti-MRP2 antibody or MK-571 and cell proliferation was examined. SUIT-2 cell proliferation was not affected by $0-25 \mathrm{ng} / \mathrm{ml}$ anti-MRP2 antibody (Fig. 7A) or by $0-20 \mu \mathrm{M}$ MK-571 (Fig. 7B). However, CDDP resistance in SUIT-2CD3 cells was diminished in the presence of anti-MRP2 antibody $(2.5 \mathrm{ng} / \mathrm{ml})$ or MK-571 $(5.0 \mu \mathrm{M})($ Fig. 7C), suggesting that MRP2 is involved in CDDP resistance in human pancreatic cancer.

\section{Discussion}

The resistance of cancer cells to anticancer agents continues to be a major problem in the treatment of non-resectable solid tumors. Particularly in advanced pancreatic cancer 


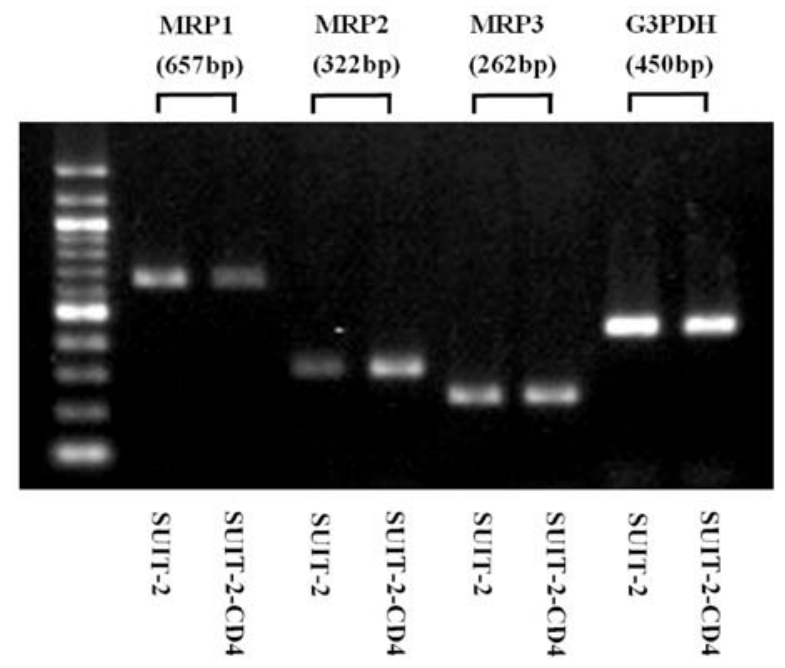

Figure 5. Change of MRP mRNA expression levels in CDDP-resistant SUIT-2 cells. Total RNA from SUIT-2 and SUIT-2-CD4 cells was extracted and amplified by RT-PCR using specific primer sets. RT-PCR analysis demonstrated that MRP2 mRNA was specifically overexpressed in SUIT2CD-4 cells compared to the parent cell line, while neither MRP1 nor MRP3 mRNA was overexpressed.

patients, positive prognoses are largely dependent on the efficacy of chemotherapy, as the majority of patients already have advanced, inoperable disease at the time of diagnosis. For many years, 5-fluorouracil was the primary therapy for patients with newly diagnosed, advanced pancreatic cancer. Recently, GEM and TS-1 have emerged as standard treatments for this disease. While combined GEM plus CDDP therapy is reported to be more active than single-agent GEM, overall response rates for this regimen are regretfully only 10.2 to $26.4 \%$ (4-6). These findings indicate that pancreatic cancer intrinsically manifests resistance to chemotherapy. Therefore, in the present study, we examined the expression patterns of multidrug resistance-associated genes in pancreatic cancer.

Our RT-PCR results demonstrated that MRP1 and MRP2 mRNA is expressed in all pancreatic cancer cell lines investigated. However, MRP3 mRNA is only expressed in the undifferentiated pancreatic cancer cell lines MIAPaCa-2 and SUIT-2. In addition, MRP3 mRNA was also not detected in five resected pancreatic cancer tissues, of which three were well-differentiated and two were moderately-differentiated cancers. These results suggest that MRP3 mRNA expression is only induced in poorly differentiated cancer and that this expression may be associated with tissue differentiation.

Although MRP1 mRNA was expressed in all pancreatic cancer cell lines, it was not detected in all pancreatic cancer tissues, despite our attempts to optimize the cycle number and annealing temperature of RT-PCR. One possible explanation for this discrepancy is that no or negligible amounts of MRP1 mRNA are expressed in pancreatic cancer tissue. Further studies are required to address this issue.

In contrast, we found that MRP2 mRNA is expressed in all pancreatic cancer tissue specimens examined. Based on the results of Wittwer et al, who reported that real-time PCR using the LightCycler system was an effective method for measuring mRNA expression levels in tissue samples (33), we performed this semiquantitative analysis for MRP2 mRNA in cancer and

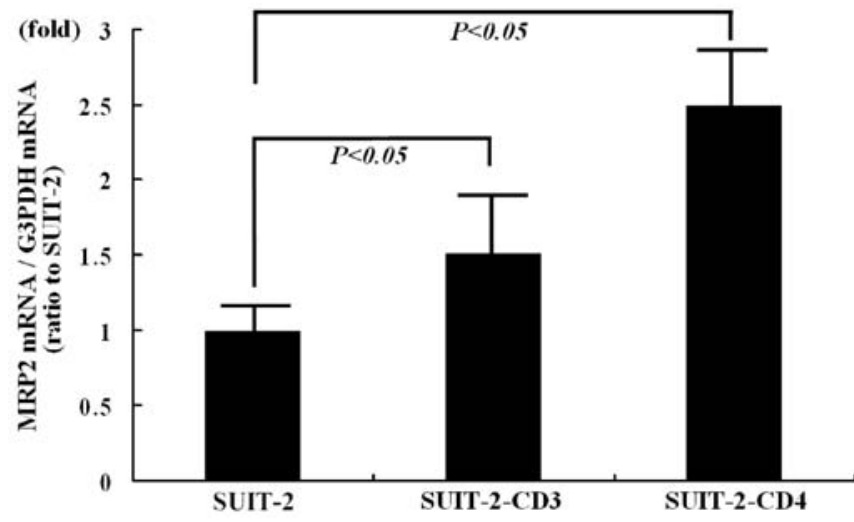

Figure 6. Induction of MRP2 mRNA in CDDP-resistant SUIT-2 cells. Total RNA from SUIT-2, SUIT-2-CD3 and SUIT-2-CD4 cells was extracted and reverse-transcribed as described in Materials and methods. Real-time PCR was performed with the LightCycler system. Induction of MRP2 mRNA expression was observed in SUIT-2-CD3 and SUIT-2-CD4 cells compared to parent cells.

normal surrounding pancreatic tissues. MRP2 mRNA expression was 1.2- to 30-fold higher in cancer lesions than in surrounding normal pancreatic tissue. In addition, immunohistochemical analysis demonstrated that MRP2 protein is present in cancer lesions, but not in normal pancreas. The tissues used in this study were obtained from chemotherapy-naïve patients, suggesting that MRP2 expression in pancreatic cancer is not related to drug exposure. Narasaki et al reported that MRP2 is expressed in various human cancer cells, including drug-resistant cells (34). Together with this study, our results suggest that MRP2 expression in pancreatic cancer may be a source of intrinsic drug resistance.

In many cancers, including pancreatic cancer, long-term chemotherapy decreases the response of cancer cells to anticancer agents. Acquired drug resistance plays an important role in this process. In the present study, we investigated acquired drug resistance using a cell inhibition assay and real-time PCR in the SUIT-2 cell line as well as CDDPresistant SUIT-2 variants. Hong et al reported that CDDPresistant lung cancer cell lines could be cultivated by continuous exposure to gradually increased CDDP doses (35). We modified this method to establish the CDDP-resistant SUIT-2-CD3 and SUIT-2-CD4 cell lines by means of continuous exposure to $10 \mathrm{nM}$ CDDP for 3 and 4 months, respectively. A cell inhibition assay confirmed that SUIT-2CD3 and SUIT-2-CD4 cells were more resistant to CDDP than was the parent SUIT-2 cell line. RT-PCR analysis revealed overexpression of MRP2 mRNA in SUIT-2-CD3 cells compared to parent cells, while real-time PCR demonstrated a 1.5-fold greater induction of MRP2 mRNA. Moreover, the CDDP resistance of SUIT-2-CD3 cells was diminished by treatment with anti-MRP2 antibody and the MRP2 inhibitor MK-571. The involvement of MRP2 in chemotherapy resistance has been shown in several previous studies. For example, Evers et al demonstrated that overexpression of MRP2 mediates vinblastine transport in polarized cells (24). Further, overexpression of MRP2 in transfected cells results in resistance to MTX (36), CDDP, 
A

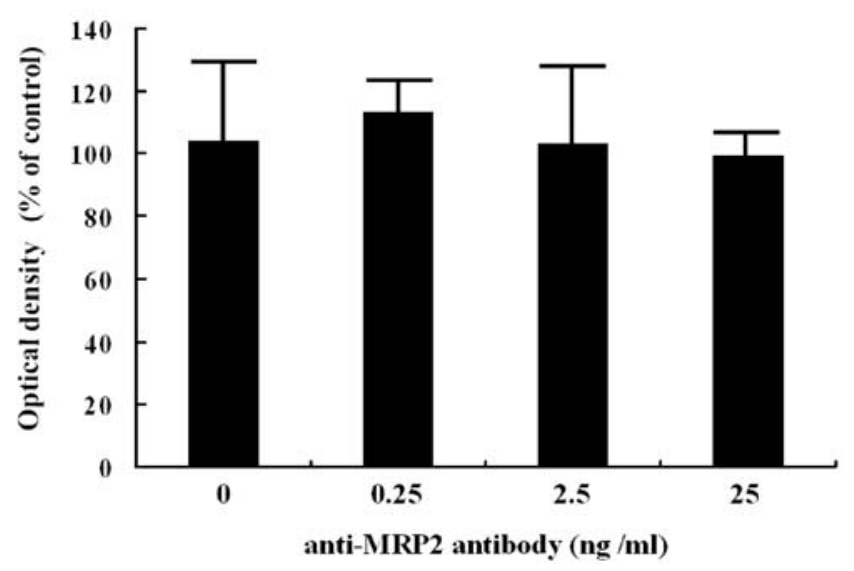

B

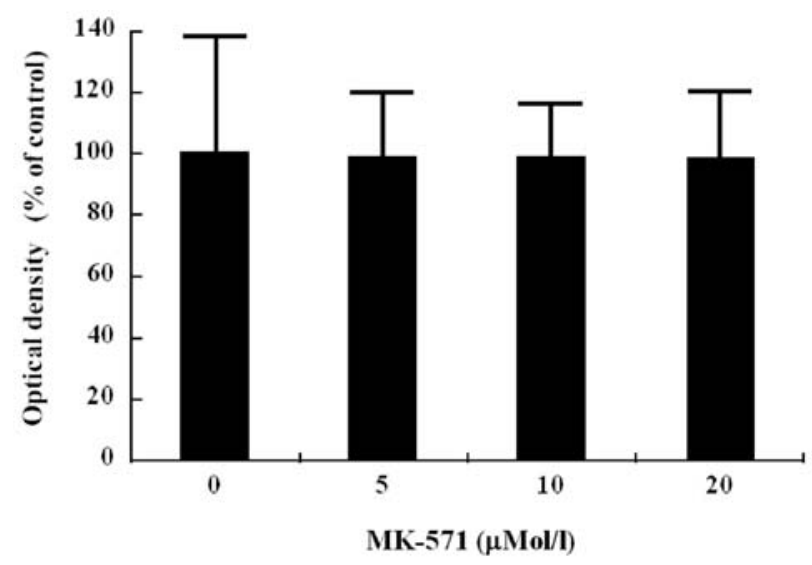

C

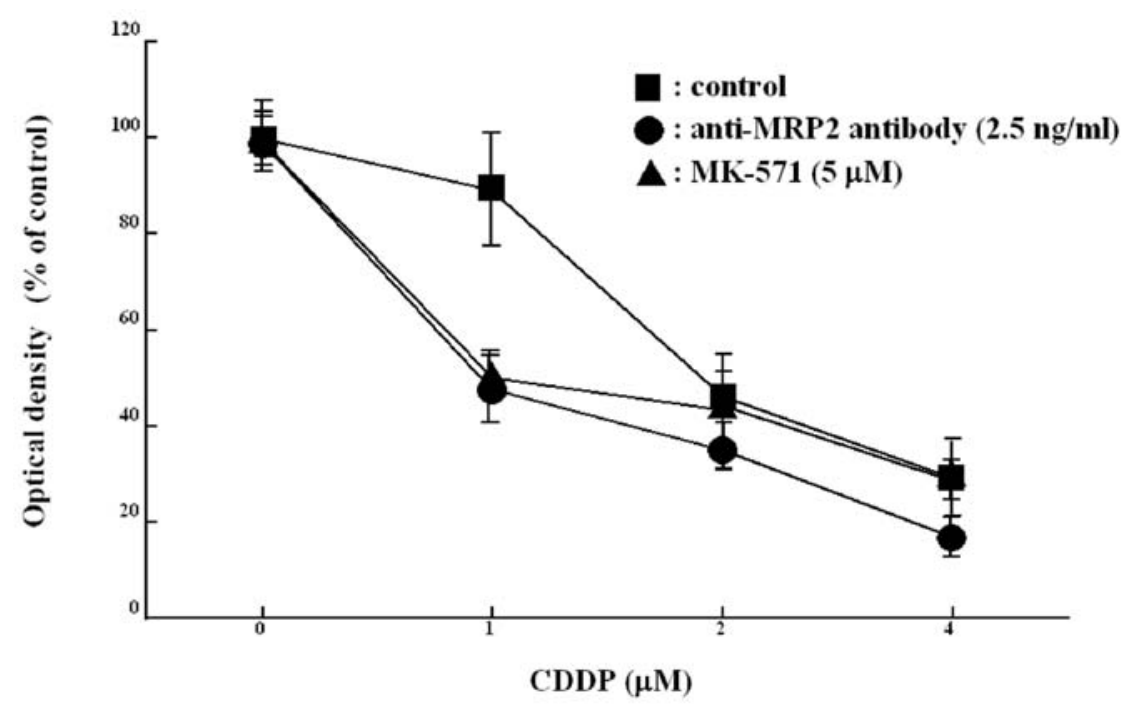

Figure 7. Reduction of CDDP resistance by anti-MRP2 antibody or the MRP2 inhibitor MK-571. (A) Anti-MRP2 antibody did not influence growth of SUIT-2 cells at concentrations of 0-25 ng/ml. (B) Similarly, MK-571 did not affect SUIT-2 cell growth at concentrations of 0-20 ng/ml. (C) CDDP resistance in SUIT-2-CD3 cells was diminished in the presence of anti-MRP2 antibody $(2.5 \mathrm{ng} / \mathrm{ml})$ or MK-571 $(5.0 \mu \mathrm{M})$.

etoposide, doxorubicin and epirubicin (37). Kuwano et al also showed that MRP2 expression is involved in drug resistance in head and neck carcinoma, hepatocellular carcinoma and colorectal carcinoma $(18,23,38)$. Together with these studies, our results suggest that MRP2 is associated with acquired resistance to CDDP, as well as with intrinsic resistance. Although SUIT-2-CD4 cells demonstrated a 1.7-fold greater induction of MRP2 expression compared to SUIT-2-CD3 cells, the degree of CDDP resistance in the two cell lines was similar. This finding indicates that acquired CDDP resistance involves other genes in addition to MRP2.

In summary, we have demonstrated that MRP2 is overexpressed in pancreatic cancer patients who have not undergone chemotherapy, as well as in CDDP-resistant pancreatic cancer cell lines. These results suggest that MRP2 is associated with intrinsic and acquired CDDP resistance in human pancreatic cancer. Moreover, MRP2 expression may be considered a novel chemoresistance marker in patients with pancreatic cancer who are being treated with CDDP-based chemotherapy.

\section{Acknowledgements}

The authors would like to thank Dr K. Morinaka, Dr K. Kariya and Y. Kuwada for helpful discussions and technical assistance. We wish to thank the Research Center for Molecular Medicine, Hiroshima University School of Medicine, for the use of their facilities. This study was supported by Grants-in-Aid from the Ministry of Education, Culture, Sports, Science and Technology of Japan.

\section{References}

1. Center for Cancer Control and Information Services, National Cancer Center, Japan.

2. Permert J, Hafstrom L, Nygren P and Glimelus B: SBU group: Swedish Council of Technology Assessment in Health Care. A systematic overview of chemotherapy effects in pancreatic cancer. Acta Oncol 40: 361-370, 2001

3. Wagman R and Gran A: Adjuvant therapy for pancreatic cancer: current treatment approaches and future challenges. Surg Clin North Am 81: 667-681, 2001.

4. Heinemann V, Quietzsch D, Gieseler F, Gonnermann M, Schonekas H and Rost A: Randomized phase III trial of gemcitabine plus cisplatin compared with gemcitabine alone in advanced pancreatic cancer. J Clin Oncol 25: 1142-1143, 2007. 
5. Bang S, Jeon TJ, Kim MH, Park JY, Park SW, Chung JB and Song SY: Phase II study of cisplatin combined with weekly gemcitabine in the treatment of patients with metastatic pancreatic carcinoma. Pancreatology 6: 635-641, 2006.

6. Colucci G, Giuliani F, Gebbia V, et al: Gemcitabine alone or with cisplatin for treatment of patients with locally advanced and/or metastatic pancreatic carcinoma. Cancer 94: 902-910, 2002.

7. Tsubouchi H, Takao S and Aikou T: Sensitivity of human pancreatic adenocarcinoma tumor lines to chemotherapy, radiotherapy and hyperthermia. Hum Cell 13: 203-212, 2000.

8. Keppler D: Export pumps for glutathione S-conjugates. Free Radic Biol Med 27: 985-991, 1999.

9. Borst P, Evers R, Kool M and Wijnholds J: A family of drug transporters: the multidrug resistance-associated proteins. J Natl Cancer Inst 92: 1295-1302, 2000.

10. Dean M, Rzhetsky A and Allikmets R: The human ATP-binding cassette (ABC) transporter superfamily. Genome Res 11: 1156-1166, 2001.

11. Gottesman MM, Fojo T and Bates SE: Multidrug resistance in cancer: role of ATP-dependent transporters. Nat Rev Cancer 2: 45-58, 2002.

12. Konig J, Nies AT, Cui Y, Leier I and Keppler D: Conjugate export pumps of the multidrug resistance protein (MRP) family: localization, substrate specificity, and MRP2-mediated drug resistance. Biophys Acta 1461: 377-394, 1999.

13. Kruh GD and Belinsky MG: The MRP family of drug efflux pumps. Oncogene 22: 7537-7552, 2003.

14. Haimeur A, Conseil G, Deeley RG and Cole SP: The MRP-related and BCRP/ABCG2 multidrug resistance proteins: biology, substrate specificity and regulation. Curr Drug Metab 5: 21-53, 2004.

15. Barrand MA, Heppell-Parton AC, Wright KA, Rabbitts PH and Twentyman PR: A 190-kilo-dalton protein overexpressed in non-P-glycoprotein-containing multidrug-resistant cells and its relationship to the MRP gene. J Natl Cancer Inst 86: 110-117, 1994.

16. Van Luyn MJ, Müller M, Renes J, et al: Transport of glutathione conjugates into secretory vesicles in mediated by the multidrugresistance protein 1. Int J Cancer 76: 55-62, 1998.

17. Loe DW, Deeley RG and Cole SP: Characterization of vincristine transported by the Mr 190,000 multidrug resistance protein (MRP): Evidence for cotransport with reduced glutathione. Cancer Res 58: 5130-5136, 1998.

18. Taniguchi K, Wada M, Kuwano M, et al: A human canalicular multispecific organic anion transporter (cMOAT) gene is overexpressed in cisplatin-resistant human cancer cell lines with decreased drug accumulation. Cancer Res 56: 4124-4129, 1996.

19. Kool M, de Haas M, Scheffer GL, et al: Analysis of expression of cMOAT (MRP2), MRP3, MRP4, and MRP5, homologs of the multidrug resistance-associated protein gene (MRP1), in human cancer cell lines. Cancer Res 56: 3537-3547, 1997.

20. Materna V, Liedert B, Thomale J and Lage H: Protection of platinum-DNA adduct formation and reversal of cisplatin resistance by anti-MRP2 hammerhead ribozymes in human cancer cells. Int J Cancer 115: 393-402, 2005.

21. Minemura M, Tanimura $\mathrm{H}$ and Tabor E: Overexpression of multidrug resistance gene MDR 1 and cMOAT in human hepatocellular carcinoma and hepatoblastoma cell lines. Int J Oncol 15: 559-563, 1999.

22. Keppler D, Leier I and Jedlitschky G: Transport of glutathione conjugates and glucuronides by the multidrug resistance proteins MRP1 and MRP2. J Biol Chem 378: 787-791, 1997.
23. Koike K, Kawabe T, Kuwano M, et al: A canalicular multispecific organic anion transporter (cMOAT) antisense cDNA enhances drug sensitivity in human hepatic cancer cells. Cancer Res 57: 5475-5479, 1997.

24. Evers R, Kool M, van Deemter L, et al: Drug export activity of the human canalicular multispecific organic anion transporter in polarized kidney MDCK cells expressing cMOAT (MRP2) cDNA. J Clin Invest 101: 1310-1319, 1998

25. Kool M, van der Linden M, de Haas M, et al: MRP3, an organic transporter able to transport anti-cancer drugs. Proc Natl Acad Sci USA 96: 6914-6919, 1999.

26. Liu B, Staren E, Iwamura T, Appert H and Howard J: Mechanism of taxotere-related drug resistance in pancreatic carcinoma. J Surg Res 99: 179-186, 2001.

27. Liu B, Staren E, Iwamura T, Appert H and Howard J: Taxotere resistance in SUIT Taxotere resistance in pancreatic carcinoma cell line SUIT 2 and its sublines. World J Gastroenterol 7: 855-859, 2001.

28. Miller DW, Fontain M, Kolar C and Lawson T: The expression of multidrug resistance-associated protein (MRP) in pancreatic adenocarcinoma cell lines. Cancer Lett 107: 301-306, 1996.

29. Fujimoto Y, Tamito S, Tsuchida A and Chayama K: Angiotensin II type 1 receptor expression in human pancreatic cancer and growth inhibition by angiotensin II type 1 receptor antagonist. FEBS Lett 495: 197-200, 2001.

30. Magaud J-P, Sargent I and Mason DY: Detection of human white cell proliferative responses by immunoenzymatic measurement of bromodeoxyuridine uptake. J Immunol Methods 106: 95-100, 1988.

31. Letschert K, Komatsu M, Hummel-Eisenbeiss J and Keppler D: Vectorial transport of the peptide CCK-8 by double-transfected MDCK2 cells stably expressing the organic anion transporter OATP1B3 (OATP8) and the export pump ABCC2. J Pharmacol Exp Ther 333: 549-556, 2005.

32. Leier I, Hummel-Eisenbeiss J, Cui Y and Keppler D: ATPdependent para-aminohippurate transport by apical multidrug resistance protein MRP2. Kidney Int 57: 1636-1642, 2000.

33. Wittwer CT, Ririe KM, Andrew RV, David DA, Gundry RA and Balis UJ: The LightCycler: a microvolume multisample fluorimeter with rapid temperature control. Biotechniques 22: 176-181, 1997.

34. Narasaki F, Oka M, Nakano R, et al: Human canalicular multispecific organic anion transporter (cMOAT) is expressed in human lung, gastric, and colorectal cancer cells. Biochem Biophys Res Commun 240: 606-611, 1997.

35. Hong WS, Saijo N, Sasaki Y, et al: Establishment and characterization of cisplatin-resistant sublines of human lung cancer cell lines. Int J Cancer 41: 462-467, 1998.

36. Hooijberg JH, Broxterman HJ, Kool M, et al: Antifolate resistance mediated by the multidrug resistance proteins MRP1 and MRP2. Cancer Res 59: 2532-2535, 1999.

37. Cui Y, Konig J, Buchholz JK, Spring H, Leier I and Keppler D: Drug resistance and ATP-dependent conjugate transport mediated by the apical multidrug resistance protein, MRP2, permanently expressed in human and canine cells. Mol Pharmacol 55: 929-937, 1999.

38. Hinoshita E, Uchiumi T, Kuwano M, et al: Increased expression of an ATP-binding cassette superfamily transporter, multidrug resistance protein 2, in human colorectal carcinomas. Clin Cancer Res 6: 2401-2407, 2000. 